\title{
The distribution and isotopic composition of dissolved chromium and trivalent chromium in the Eastern Tropical North Pacific oxygen deficient zones
}

\author{
TIANYI HUANG ${ }^{1,2}$, EDWARD A. BOYLE ${ }^{1}$
}

${ }^{1}$ Massachusetts Institute of Technology, Cambridge, MA, 02139

${ }^{2}$ MIT/WHOI Joint Program in Chemical Oceanography,

Woods Hole, MA

The Eastern Tropical North Pacific (ETNP) is the largest oxygen deficient zone (ODZ) in the global ocean where various redox processes and unique microbial activities occur. $\mathrm{Cr}(\mathrm{VI})-\mathrm{Cr}(\mathrm{III})$ is one of the redox pairs that undergoes transformations in the ODZ. We collected filtered seawater samples from 6 stations $\left(15.1^{\circ} \mathrm{N}-21.5^{\circ} \mathrm{N}, 105.7^{\circ} \mathrm{W}-110^{\circ} \mathrm{W}\right)$ in the ODZ from two cruises (RR1805, April 2018; KM19-20, Sept 2019) to study $\mathrm{Cr}$ reduction with $\mathrm{Cr}$ isotopes. All stations show a slight $[\mathrm{dCr}]$ depletion and heavier $\delta^{53} \mathrm{Cr}$ in the upper core of the ODZ $\left(\sigma_{0} \sim 26.3 \mathrm{~kg} / \mathrm{m}^{3}\right)$. At roughly the same depths at the stations where $\mathrm{Cr}$ (III) was analyzed, a maximum was observed with a lighter isotopic composition than $\mathrm{dCr}$, with a calculated isotopic fractionation of $-1.5 \%$. At this density layer, we also see maximum accumulation of other reduced species such as Fe(II) and nitrite, which might indicate some coupling between $\mathrm{Cr}$ reduction with these redox species or common microbial mediation involvement. We also found $\mathrm{Cr}$ (III) concentration differences between stations, which was also observed for $\mathrm{Fe}$ (II) and nitrite. This inter-station difference may be caused by differences in the intensity of microbial activities, progressive accumulation of product, or differences in the impact of lateral advection from the shelf. 